\title{
A VIOLÊNCIA DE GÊNERO E O PROCESSO SAÚDE-DOENÇA DAS MULHERES
}

\author{
The violence of gender and health-disease \\ process of women
}

\section{La violencia de género y el proceso salud-enfermedad de las mujeres}

Rebeca Nunes Guedes ${ }^{1}$
Ana Tereza Medeiros Cavalcanti da Silva ${ }^{2}$

\section{RESUMO}

Trata-se de um estudo que teve como objetivo compreender e analisar as repercussões da violência conjugal no processo saúdedoença das mulheres. Ė resultado da reanálise do material obtido em uma investigaçãa por meio de entrevistas com mulheres em situação de violência e de denúncia, na Delegacia da Mulher no Município de João Pessoa - PB. A análise dos discursos evidenciou que a violência conjugal é um fenômeno social recorrente e multifacetado que influencia significativamente a saúde das mulheres que a vivenciam. Seu enfrentamento exige dos profissionais de saúde o reconhecimento de que a violência é um problema de saúde coletiva que perpassa todas as dimensões das relações sociais, cujas raízes encontram-se nas desigualdades de gênero. Tal fenômeno necessita de ser captado, compreendido e combatido em todas as dimensões da realidade social.

Palauras-chave: Violência contra a Mulher. Gênero e Saúde. Violência Doméstica. Processo Saúde-Doença.

\begin{abstract}
It is about a study that had as objective to understand and to analyze the repercussions of the conjugal violence in the process health-illness of the women. It's a result of analyses of the material gotten in an inquiry by means of interviews with women in situation of violence and denunciation, in the Police station of the Woman in the City of João Pessoa - PB (Brazil). The analysis of the speeches evidenced that the conjugal violence is a recurrent and multifaceted social phenomenon that significantly influences the health of the women who lived it. Its confrontation demands from the health professionals, the recognition of this violence as a problem of collective health that crosses all the dimensions of the social relations, whose roots meet in the inequalities of gender. Such phenomenon needs to be caught, understood and fought in all the dimensions of the social reality
\end{abstract}

Key words: Violence Against Women. Gender and Health. Domestic Violence. Health-Disease Process

\section{Resumen}

Tratase de un estudio cuyo objetivo fue analizar y comprender el impacto de la violencia conyugal en el proceso saludenfermedad de las mujeres. Es resultado de la revisión del material obtenido en una investigación a través de entrevistas con mujeres en situación de violencia y abuso, en la Comisaría de Policía de la Mujer en la ciudad de João Pessoa - PB (Brasil). El análisis de los testimonios evidenció que la violencia conyugal es un fenómeno social multifacético recurrente y que influye en forma significativa en la salud de las mujeres que vivencian esta experiencia. Confrontar esta problemática exige que los profesionales de la salud reconozcan que la violencia es un problema de salud colectiva que sobrepasa todas las dimensiones de las relaciones sociales, cuyas raíces están en la desigualdad de género. Este fenómeno debe ser comprendido y combatido en todas las dimensiones de la realidad social.

Palabras clave: Violencia contra la Mujer. Género y Salud. Violencia Doméstica. Proceso Salud-Enfermedad

${ }^{1}$ Enfermeira, Mestre em Enfermagem pela Universidade Federal da Paraíba. Doutoranda do Programa Interunidades de Doutoramento em Enfermagem dos campi de São Paulo e Ribeirão Preto da Universidade de São Paulo. Brasil. E-mail: rebecanunesguedes@usp.br, ²Enfermeira. Doutora em Enfermagem pela Escola de Enfermagem da Universidade de São Paulo. Professora Adjunta do Departamento de Enfermagem em Saúde Pública e Psiquiatria da Universidade Federal da Paraíba. Brasil. E-mail: anatmc8@yahoo.com.br, ${ }^{3}$ Enfermeira. Professora Titular do Departamento de Enfermagem em Saúde Coletiva da Escola de Enfermagem da Universidade de São Paulo. Orientadora do Programa Interunidades de Doutoramento em Enfermagem dos campi de São Paulo e Ribeirão Preto da Universidade de São Paulo. Pesquisadora I do CNPq. Brasil. E-mail: rmgsfon@usp.br 


\section{INTRODUCÃO}

A perspectiva do Sistema Único de Saúde (SUS) tem tornado visíveis possibilidades de mudanças na área de saúde, entre as quais a consciência sobre a necessidade de adoção de abordagens teóricas e práticas profissionais emancipatórias, que se manifestam no reconhecimento das limitações do modelo de saúde pública tradicional por seu enfoque predominantemente biológico. A proposta do SUS comporta a teoria da determinação social do processo saúde-doença, que compreende a saúde-doença como fenômeno que se determina na esfera da vida social.

A desigualdade de gênero constitui uma das grandes contradições da sociedade que se mantém ao longo da história da civilização e tem colocado as mulheres em um lugar social de subordinação. Essa desigualdade tem como uma de suas extremas formas de manifestação a violência contra as mulheres, que é resultado de uma assimetria de poder que se traduz em relações de força e dominação. Desse modo, a violência baseada no gênero tem se constituído em um fenômeno social que influencia sobremaneira o modo de viver, adoecer e morrer das mulheres.

Em pesquisas de base populacional, realizadas em todo o mundo, entre $10 \%$ e $64 \%$ das mulheres afirmaram terem sido objeto de agressão física por parte do parceiro masculino em algum momento de sua vida. ${ }^{1} A$ violência contra a mulher pode se manifestar de vários modos e em diferentes graus de severidade. "Suas formas mais atrozes e condenáveis geralmente ocultam outras situações menos escandalosas, por se encontrarem prolongadas no tempo e protegidas por ideologias ou instituições aparentemente respeitáveis" 2:14 Porém, essas formas de violência consideradas mais sutis, silenciadas no interior das relações conjugais, causam tantos ou mais danos às mulheres que suas formas de manifestações mais visíveis.

Partindo do fato de que a violência afeta significativamente o processo saúde-doença das mulheres, podemos considerar o setor saúde como locus privilegiado para identificar, assistir e referir as mulheres vitimizadas. Ao longo de suas vidas, as mulheres que vivenciam violência doméstica ou sexual apresentam mais problemas de saúde, geram mais custos de atenção sanitária e buscam, com mais frequência, os serviços hospitalares e de urgência que outras pessoas que não sofrem maus tratos. ${ }^{1}$

Nos serviços de saúde, muitas vezes, evidenciam-se três aspectos cujas intersecções potencializam os efeitos da violência e ampliam seu campo de atuação: o primeiro diz respeito ao fato de a mulher não denunciar a agressão sofrida, seja ela física ou psicológica, apresentando apenas queixas vagas e recorrentes nos serviços de saúde, referentes aos danos físicos. Depois, há o fato da predominância de uma qualidade tradicional da assistência pautada por heranças de programações de saúde e formação profissional fragmentada e biologicista. Há, ainda, a influência do modo como foram construídas as identidades de gênero, impregnadas de estereótipos que designam, para as mulheres, lugares de obediência e submissão. Esses três aspectos inter-relacionados na dinâmica da realidade social produzem a invisibilidade do impacto da violência sobre a saúde das mulheres.

Outras vezes, mesmo quando a situação de violência é diagnosticada, ela não é devidamente valorizada, pois o saber instrumental que orienta as práticas profissionais está voltado para tratar, sobretudo, os danos físicos. Todavia, questões subjetivas como a vulnerabilidade emocional e a desproteção são sentimentos que afetam a saúde mental e fragilizam a capacidade das vítimas de violência doméstica para o enfretamento do problema. Este é extensivo ao espaço público, quando, por exemplo, a mulher não consegue nem mesmo verbalizar, para um profissional que a atende, que é vítima de violência doméstica. Desse modo, a inadequação do saber instrumental constitui um óbice para o desenvolvimento de um processo de trabalho em saúde transformador da realidade. ${ }^{3}$

0 presente artigo constitui um reolhar de parte dos resultados da pesquisa intitulada Violência conjugal: problematizando a opressão das mulheres vitimizadas sobo olhar de gênero ${ }^{4}$ e tem como objetivo apresentar as repercussões que a violência conjugal traz para o processo saúde-doença das mulheres. Nesse sentido, partimos de uma aproximação com as mulheres que vivenciam situações de violência, de modo a conhecer sua convivência com esse tipo de opressão, para verificar as repercussões que incidem em seus processos de vida.

Entendemos que o aprofundamento da compreensão de investigações sobre essa temática pode trazer uma visão peculiar da questão da violência conjugal e seus desdobramentos na vida das mulheres, sobretudo quando envolve os profissionais de saúde e revela os limites do saber tradicional que se mantêm orientando as práticas profissionais, como saber instrumental, apesar da proposta de um novo modelo de assistência à saúde integral e equânime.

\section{MÉTODO}

\section{Caracterização e cenário do estudo}

Trata-se de uma pesquisa de abordagem qualitativa cujos elementos do objeto de estudo foram analisados a partir da perspectiva de gênero.

A categoria gênero pressupõe a construção histórica das relações sociais entre os sexos, diferenciando o sexo biológico do sexo social. 0 sexo social, historicamente construído, é produto das relações sociais entre homens e mulheres e deve ser entendido como elemento constitutivo destas relações, nas quais as diferenças são tidas como naturais e inquestionáveis.

Uma análise mais profunda dessas relações revela condições de poder extremamente desiguais, nas quais as mulheres vêm ocupando posições subalternas e secundárias. A categoria gêneropode explicar, àluz das relações de poder, as contradições das construções das relações sociais entre homens e mulheres 
e o seu impacto sobre o processo saúde-doença do grupo em desvantagem, composto pelas mulheres. ${ }^{5}$

0 estudo foi realizado no Município de João Pessoa - PB, na Delegacia Especializada de Atendimento à Mulher (DEAM), durante o período de 20 de abril a 24 de maio de 2006. Para a produção do material empírico, foram consideradas as mulheres em situação de violência conjugal, no momento em que realizavam a denúncia.

\section{Sujeitos da pesquisa, produção do material empírico e aspectos éticos envolvidos}

As mulheres entrevistadas foram aquelas que, durante os meses de abril e maio de 2006, estiveram na DEAM em situação de denúncia contra violência conjugal e apresentaram interesse em participar do estudo, assim como disponibilidade de tempo e estado emocional que permitisse a realização do processo de entrevista.

Os depoimentos foram gravados em fitas-cassete e logo após cada entrevista eram transcritos naíntegra, acompanhados de observações sobre os diferentes momentos da entrevista. Após cada transcrição, procedemos a pelo menos duas leituras de cada texto, marcando os principais temas, as recorrências, as repetições e as redundâncias mais evidentes. Posteriormente, no processo de análise mais aprofundado, essas marcações serviram de guia para desvelar posições sociais apresentadas pelas mulheres, que ofereciam possibilidades de revelar visões de mundo, valores e sentimentos capazes de expressar o fenômeno em sua magnitude por aquelas mulheres diante dos objetivos da pesquisa. Desse modo, ao completar oito entrevistas, observamos que o material permitia analisar o fenômeno recortado, razão pela qual a coleta foi encerrada.

Aidade das participantes variou entre 21 e 41 anos; cinco eram solteiras, duas casadas e uma divorciada; apenas uma não possuía filhos; a maioria era católica; uma participante tinha o ensino superior concluído, duas concluíram o ensino médio, uma tinha o ensino médio incompleto, três, o ensino fundamental incompleto, e uma se declarou analfabeta.

Em relação à profissão das participantes apontamos: uma comerciante, uma professora, uma cabeleireira, uma doméstica, uma vendedora ambulante, uma auxiliar operacional e duas "do lar"; em relação ao grau de parentesco com os agressores, foram identificados: dois companheiros, um cônjuge, quatro excompanheiros e um ex-cônjuge.

0 estudo, em todas as etapas, atendeu aos requisitos propostos pela Resolução 196/96 do Conselho Nacional de Pesquisa que dispõe sobre as normas e diretrizes regulamentadoras da pesquisa envolvendo seres humanos. ${ }^{6} 0$ projeto de pesquisa foi aprovado pelo Comitê de Ética e Pesquisa do Centro de Ciências da Saúde da Universidade Federal da Paraíba, em Reunião Ordinária realizada no dia 16/02/2006, sob protocolo $261 / 06$.

\section{Análise do material empírico}

A análise do material empírico teve início depois da transcrição do material produzido pelas entrevistas, impressão e leitura dos textos. Subsequentemente, houve releituras dos textos e identificação dos temas sob o enfoque de gênero. Em seguida, foi feito o recorte dos textos que continham os temas que orientaram a construção das subcategorias, considerando o objeto e os objetivos deste estudo. Em todo o processo de análise e discussão, o material empírico foi relacionado com a literatura pertinente, para ancorar as posições sociais nele reveladas, conforme a orientação para a análise crítica do discurso ${ }^{7}$ na qual os textos são analisados, não para responsabilizar individualmente as pessoas, mas para se identificar determinadas posições sociais que se manifestam discursivamente no interior da sociedade, marcadas pela ideologia.

Seguindo essa orientação metodológica de análise, identificamos os temas emergentes dos discursos que permitiram a organização dos blocos de significados. Estes orientaram a construção das seguintes subcategorias empíricas: A assimetria de poder impondo submissão e silêncio das mulheres em situação de violência; O duplo da violência: dominação e possibilidade de desconstrução do modo idealizado hegemonicamente de casamento; O impacto da violência no processo saúde-doença das mulheres vitimizadas. Ao término dessa etapa do processo de análise, verificamos que as subcategorias poderiam ser acolhidas em um grande conceito ou categoria maior: A violência conjugal e sua relação com a tutela da diferença nas relações desiguais de gênero.

Visando atender o objetivo proposto para este artigo, será apresentada a subcategoria empírica construída a partir dos temas e discursos revelados nos depoimentos das participantes, que diz respeito às repercussões da violência conjugal no processo saúde-doença das mulheres que a vivenciam.

\section{RESULTADOS E DISCUSSÃO}

\section{O impacto da violência no processo saúde-doença das mulheres vitimizadas}

A observação da realidade e os depoimentos das mulheres demonstram que uma grande parcela delas está distante das condições aceitáveis de saúde quando consideramos suas múltiplas dimensões.

Uma vez que a violência conjugal é a forma predominante de violência praticada contra as mulheres em todo o mundo, o problema assume magnitude no espaço das relações conjugais, no qual a violência assume características de episódios recorrentes e em uma escalada cada vez de maior gravidade. ${ }^{8}$

Os depoimentos das mulheres revelaram consequências negativas da violência experimentada em suas relações conjugais, com repercussão em todos os aspectos de suas vidas, a exemplo das declarações que seguem, mostrando os agravos de ordem física como uma das consequências da violência realizada contra a mulher: 
Eu já tive até um problema de AVC e paralisia facial devido a tanto estresse. (E1).

Dentro destes três anos emeio, eu perdidois bebês, de muita raiva. (E2).

Asaúde foia pior de todas, porque eu fiqueicardíaca, nervosa; minha pressão é altíssima. (E2).

Eu sou hipertensa, aíse agrava mais, porque ontem, pra eu dormir, tive que tomar Diazepam, porque, senão, eu não tinha dormido com a minha pressão lá em cima. (E3).

Os depoimentos revelam a ansiedade decorrente da violência, desencadeando diversos danos de ordem física. As mulheres atribuem à violência a causa desses agravos, demonstrando seu reconhecimento sobre o impacto que a violência representa para sua saúde. Os agravos, assinalados nos depoimentos que seguem, são de ordem física e emocional com severas repercussões também na saúde mental.

Tanta coisa... [choro] Eu estou com depressão (E4).

Ehoje eu sou muito nervosa, não tenho condições de falar com ninguém, me tranco dentro do quarto e ficoláo dia todinho (E2).

[...] Eu fico tão sufocada..., com qualquer coisinha eu já estou me tremendo, eu já fico nervosa, fico chorando. Ele não pode tomar um gole de cerveja que eujá fico me acabando (E5).

[...] Ele bom não me esculhambava, era mais quando estava embriagado, então eu passei a ser uma pessoa muito nervosa, compulsiva por demais [...] cheguei a engordar 20 quilos[...](E6)

Os depoimentos denunciam a pressão emocional à qual as mulheres vítimas de violência conjugal estão submetidas, acarretando distúrbios da ansiedade e depressão. Os depoimentos também revelam o alcoolismo como possível agravante ou desencadeante da violência. Em relação ao alcoolismo, na relação onde há violência, estudos demonstram a forte associação entre o uso de álcool e a ocorrência de agressões efetuadas no contexto das relações conjugais. Porém, a utilização do álcool não faz mais que acentuar o teor da violência. ${ }^{9,10}$

A ansiedade e o temor caracterizam a vida da pessoa insegura, dependente ou ameaçada, sendo essas características comumente encontradas na vida de mulheres em situação de violência. ${ }^{11}$ Entre as manifestações que afetam a saúde mental, têm sido assinaladas, por diversos estudos, as seguintes: desordem do estresse pós-traumático, medo, fadiga, depressão, ansiedade, disfunção sexual, desordens de alimentação, desordens múltiplas de personalidade e distúrbios do sono. ${ }^{1,11}$
0 depoimento a seguir mostra que a situação de opressão também nega à mulher a possibilidade de viver a sexualidade de maneira satisfatória, demonstrando, também, a negação de seus direitos sexuais, através do poder masculino sobre seu corpo sua vontade:

[...] Portanto estresse, eu perdia vontade de fazer sexo[...]. Cheguei e conversei com ele. Eu já não estava querendo mesmo, há algum tempo, com tanta agressividade, a gente vaitomando até abuso, aínão sei se juntou medicamento, se foipsicológico mesmo ou estresse de tanto trabalho... abuseil Não queria nada com ele e também não tinha vontade com ninguém [...] Aí quando foi uma noite, ele decidiu fazer sexo comigo e eu saí correndo e ele correndo atrás de mim. Quando eu vique ele estava altamente agressivo, aí eu parei e disse: 'Faça, eu estou aquil' Aí comecei a chorar, me deu aquela raiva tão grande dentro de mim, parecia que a minha mente estava paralisada, uma coisa tão estranha, eu fiquei tão nervosa. Aí foi que eu fiquei com mais abuso e fui obrigada a fazer, morrendo de medo de uma gravidez[...] quando ele terminou de fazer eu só fazia chorar [...] aí veio meu problema de paralisia, começou a dar esquecimento e eu tenho certeza que foi a partir daquele dia. (E1).

0 depoimento revela a sexualidade feminina seriamente comprometida na vida das mulheres vitimizadas, traduzida aqui pela ausência do desejo sexual pelo parceiro, como também por qualquer pessoa. O discurso revela o poder total do parceiro sobre o corpo e a vontade das mulheres, manifestado por estupro conjugal, ainda que socialmente legitimado, trazendo sérias consequências para a vida das mulheres.

É importante ressaltar que a violência conjugal é um fenômeno que ocorre também em relações permeadas por afetos, na qual são depositadas as expectativas que giram em torno do ideal de família e de casamento. Sendo o agressor uma pessoa com quem a vítima compartilha sua vida, divide e constitui o seu lar, isso faz da violência conjugal um fenômeno ainda mais importante, uma vez que implica sentimentos de impotência, decepção, desamor e desesperança. No depoimento que segue, E2 mostra a perda de autoestima e de seu ânimo em relação à vida, ocasionada pela violência, que destruiu sua relação conjugal e seus sonhos em torno do ideal de casamento.

Eu não tenho ânimo pra nada[...] tudo pra mimé um zero à esquerda[...] eu tenho vergonha de sair de casa. Para mim o mundo não existe, só existeo meu quarto, minha televisão, minha cama e o banheiro que é em frente [...] Dá vontade de fugir pro alto. Eu trabalhava, e agora, no momento, eu não posso trabalhar porque sou nervosa, tomo 
Lexotan de 6 mg devido a tanto problema decorrente do meu casamento[...]. Quase tudo eu perdie agora eu me acho velha. 27 anos, pra o campo de trabalho vocêjátávelha[...] Então eu me sinto velha, acabada, não tenho nervos.(E2).

A partir dos depoimentos, podemos observar as consequências que a violência trouxe para a autoestima e também para a vida social e econômica. A produção e a reprodução da vida social encontram-se seriamente comprometidas pelo trauma decorrente da violência vivenciada. Decepção, revolta, autoimagem distorcida e baixa autoestima são sentimentos que emergem dos discursos, assim como a ausência de prazer nas atividades da vida social.

Os depoimentos das participantes também revelaram a multiplicidade de papéis que a mulher acumula ao trabalhar no mundo público, sem que suas obrigações no mundo privado do lar sejam reduzidas e mesmo consideradas, sendo este um fator gerador de desgastes, o que também traz consequências indesejáveis para a sua saúde-doença.

Nos últimos anos, presenciamos muitas conquistas resultantes da luta feminina contra a desigualdade de gênero. O espaço no trabalho do mundo público é uma delas e, apesar da realidade nos demonstrar que ainda estamos distantes de condições plenas de igualdade entre homens e mulheres, no mercado de trabalho é visível a crescente conquista das mulheres de maior qualificação profissional e melhores espaços no mercado de trabalho. Porém, essa conquista ocorreu sem que, no mundo privado, houvesse transformações significativas nas relações de gênero, como a redução de suas obrigações e 0 compartilhamento de tarefas concernentes aos cuidados com a casa e a família. Isso resulta em uma dupla e, às vezes, ininterrupta, jornada de trabalho feminino como realidade na vida de mulheres que acumulam papéis nas duas esferas.

A ideologia hegemônica legitima o papel da mulher como cuidadora familiar e, mesmo quando elas compartilham a provisão econômica do lar ou até são as únicas provedoras econômicas da família, ainda lhes é destinado o cuidado com os filhos, com o marido e a responsabilidade com as tarefas domésticas do lar. 0 depoimento a seguir demonstra essa realidade, enfatizando, ainda, a exigência do parceiro pelo cumprimento de atividades, acumuladas nos âmbitos público e privado, pela esposa.

Olar dele, entre aspas, era assim: uma mulher que cozinhava, passava, fazia café [...] que organizasse a vida dele da semana todinha: chegar do trabalho, almoçar. Chegar da universidade ejantar. Ele queria uma mulher desse jeito. Equeria uma mulher que também trabalhasse fora pra também dar dinheiro a ele. (E2).

As responsabilidades das mulheres, no que diz respeito aos cuidados domésticos e familiares, levam-nas a um estado de "hipervigilância", que pode ser traduzido como um agravo de saúde mental, uma vez que pode ser a causa de transtornos da ansiedade, quando não há possibilidade de apoio. ${ }^{9-11}$
O peso da tripla jornada é considerado um dos processos destrutivos da vida das mulheres, nas suas tentativas de conseguir condições de sobrevivência familiar, sendo esta tripla jornada constituída pelo trabalho remunerado, pelos cuidados domésticos e com as crianças e pelo trabalho relativo à geração de novos sujeitos sociais, sem a participação masculina. ${ }^{12}$

As mulheres têm sua saúde fragilizada pela carga de trabalho, associada à violência, desde suas formas mais sutis, até suas manifestações mais visíveis. Ao recorrer a um profissional de saúde, na busca de cuidados aos agravos decorrentes da violência, E1 mostra, em seu discurso, a identificação, pelo profissional de saúde, da violência como causa dos agravos que a acomete.

Eu fuipro médico, pro meuneurologista, e ele disse assim: "Olhe, o melhor remédio, se você quiser ficar boa... saia de casa" (E1).

0 depoimento revela o profissional de saúde indicando uma possibilidade de transformação, afirmando ser o abandono da relação o melhor caminho para restabelecimento de sua saúde. Porém, apesar de captar a violência como causa dos agravos, esse profissional assume uma atitude prescritiva para com a vida da mulher, desconsiderando-a como um sujeito de sua própria história. Apesar de o profissional ter razão na essência de seu aconselhamento, pois livrar-se da causa do problema certamente seria uma atitude eficaz, a vida de relações é complexa e não pode ser resolvida com soluções simplistas. Pesquisas revelam que a violência como causa de agravos é pouco apreendida pelos profissionais de saúde como um fenômeno complexo. ${ }^{8,12,13}$

No depoimento a seguir, E2 revela a banalização da violência e de seu sofrimento, por ocasião de um atendimento de saúde:

Quando eu fuipra minha cardiologista, que eu fiquei assim com problemas cardíacos, por causa de muito sofrimento, ela disse: 'isso énormal, nervosismo é assim mesmo', e que eu tinha que superar tudo isso, que a vida é assim e que todo mundo passa porisso. (E2).

Esse depoimento revela a reprodução institucional da naturalização e banalização da violência contra a mulher por parte do profissional de saúde a quem E2 recorreu. Sublinhamos o fato de que a profissional a quem ela se refere é uma mulher. Há mulheres profissionais de saúde que trazem para o cotidiano da atenção à saúde das mulheres as marcas da construção da identidade de gênero ${ }^{13}$, aqui traduzidas pela orientação da aceitação da ordem constituída nas relações dominantes de gênero, ao recomendar o suportar feminino das amarras decorrentes da opressão masculina. Ao considerar a vivência de E2 como uma situação normal, pela qual todo mundo passa, a profissional de saúde demonstra que a naturalização da 
violência também é introjetada no imaginário feminino, independente da classe social e do nível de escolaridade, fato que, nessa situação, gera outro tipo de violência, traduzida pela omissão de cuidados efetivos, solidariedade e proteção, além de dificultar o exercício da prática profissional como instrumento de emancipação social e de transformação do status quo.

As consequências da violência contra as mulheres não têm sido reconhecidas, diagnosticadas nem tratadas da devida forma, em parte, em virtude do estigma social que permeia o fenômeno. Frequentemente, "o olhar do profissional de saúde, impregnado de estereótipos sociais, deixa de enxergar os efeitos sobre a saúde, de formas de violência como as agressões de maridos sobre mulheres"14.

Estudos com mulheres vítimas de violência conjugal demonstraram que as mulheres que relataram a busca de assistência em algum serviço de saúde não foram atendidas em rotinas de atenção sensíveis à abordagem da violência doméstica e sexual e, também, que a maioria dos serviços não dispõe de protocolos de atenção à violência contra a mulher. ${ }^{15}$ Contudo, "a subalternidade social feminina reflete-se diretamente nas condições de adoecer e morrer, tanto quanto nos consumos dos serviços de saúde que muitas vezes são tão deletéricos quanto às condições de vida que determinam os agravos [...] Pior que as estatísticas de morbimortalidade é a naturalização disto, materializada no descaso dos setores, seja o da saúde, responsável pelas políticas públicas específicas, seja o jurídico, responsável pela punição dos culpados". 12:457

Constatamos que a violência conjugal acarreta consequências significativas para a vida das mulheres que vivenciam situações de violência. Estas procuram regularmente os serviços de saúde, seja em razão das consequências físicas imediatas da agressão, seja por agravos consequentes da situação vivida. Por ser um problema permeado por contradições decorrentes das desigualdades resultantes da construção social de gênero, o fenômeno exige uma abordagem sensivel e generificada. ${ }^{16}$

Nas décadas de 1980 e 1990, a Epidemiologia Crítica aumentou a busca para compreender as causas dos agravos, tendo como uma de suas hipóteses a correlação entre saúdedoença e categorias sociais como classe social, gênero, raça e geração. 0 enfoque explica as determinações mais profundas que operam sobre os diferentes grupos sociais e determinam diferentes perfis de saúde e de doença segundo a sua forma de inserção na sociedade. ${ }^{17}$

Nessa perspectiva, o enfrentamento da violência de gênero como fenômeno destrutivo da vida das mulheres, como grupo social, deve considerar as dimensões estrutural, particulare singular da realidade objetiva, sendo fundamental que os serviços de saúde passem a se preocupar com o enfoque, procurando identificá-lo e compreendê-lo em profundidade para enfrentá-lo de forma diferente do modo hegemônico que, sobretudo, reproduz a ideologia opressora dominante.

\section{CONSIDERAÇÕES FINAIS}

A violência constitui um fenômeno que tem interfaces com a Saúde Coletiva, pois desponta como uma contradição na vida das mulheres, gerando tensão e resultando em processos destrutivos do seu processo saúde-doença, como podemos observar nos discursos que emergiram dos depoimentos das participantes. A luta pela ampliação dos espaços de liberdade e de produção social da vida das mulheres deve ter como eixo norteador uma ruptura com a tradição do modelo de assistência hegemônico, de modo que a superação dessa realidade implica luta, enfrentamento nos planos político, ideológico, técnico, cultural e social.

Ao confirmar as consequências que a violência traz para saúde-doença das mulheres, ressaltamos a necessidade de preparo dos profissionais de saúde para lidar, de forma sensível e eficaz, com as mulheres que buscam os seus cuidados. Assinalamos, também, que seu enfrentamento não deve ser centralizado no tratamento de suas consequências, mas na sua prevenção primária. Atualmente, o modelo de atenção, tendo como centro a família, coloca os profissionais de saúde em posições estratégicas que permitem o desenvolvimento de mecanismos que possibilitam a conscientização e 0 empoderamento das mulheres para desconstruir a desigualdade estabelecida e reconstruir relações equitativas de gênero.

A perspectiva do Sistema Único de Saúde (SUS) orientada por princípios revestidos de conteúdos e valores inovadores com o conceito ampliado de saúde, ação intersetorial e integralidade da atenção e equidade tem reconhecido as limitações do modelo de saúde pública tradicional que utiliza, sobretudo, os diagnósticos epidemiológicos tradicionais como instrumento para identificar as necessidades de saúde da população, ignorando aquelas necessidades socialmente produzidas, como as que determinam a violência doméstica.

Sendo assim, os melhores níveis de saúde não serão alcançados se as transformações não envolverem o setor saúde, por meio do envolvimento de outras áreas igualmente comprometidas com as necessidades sociais e com os direitos de cidadania. Sendo a violência um problema de múltiplas faces, que tem suas raízes na construção histórica, cultural e social das relações de gênero, sua prevenção deve-se fundamentar na desconstrução e reconstrução dessas relações perante os indivíduos, as famílias, as comunidades e a sociedade como um todo, para que se possam elaborar e desenvolver estratégias eficazes de prevenção e enfrentamento e tornar possível levar essa compreensão aos espaços sociais, onde a violência é construída e legitimada. 


\section{REFERÊNCIAS}

1 Organização Pan-americana de Saúde- OPS. Informe mundial sobre la violencia y la salud: resumen. Washington, DC(USA); 2002.

2 Minayo MCS. Violência: um problema para a saúde dos brasileiros. In: Ministério da Saúde (BR). Impacto da violência na saúde dos brasileiros. Brasília (DF); 2005: 9-41.

3 Silva ATMC. A reforma psiquiátrica em João Pessoa (PB): limites e possibilidades de transformação do trabalho para produzir saúde mental. [tese de doutorado] São Paulo (SP): Escola de Enfermagem/ USP; 2003.

4 Guedes RN. Violência conjugal: problematizando a opressão das mulheres vitimizadas sob olhar de gênero. [dissertação de mestrado]. João Pessoa (PB): Centro de Ciências da Saúde/ UFP; 2006.

5 Fonseca RMGS. Gênero e saúde da mulher: uma releitura do processo saúde doença das mulheres. In: Fernandes RAQ, Narchi NZ, organizadoras. Enfermagem e saúde da mulher. São Paulo (SP): Manole; 2007. p. 30-61.

6 Ministério da Saúde (BR). Conselho Nacional de Saúde. Resolução n 196 de 10 outubro de 1996. Diretrizes e normas regulamentadoras de pesquisa envolvendo seres humanos. Brasília (DF); 1996.

7 Fiorin JL, Savioli FP. Para entender o texto: leitura e redação. São Paulo (SP): Ática; 1999.

8 Heise L. Gender-based abuse: the global epidemic. Cad Saude Publica. [on-line]. [citado 5 maio 2006] Disponível em: http:// unw.scielosp.org/scielo.
9 Soares LE, Soares BM, Carneiro LP. Violência contra a mulher: as DEAMs e os pactos domésticos. In: Soares LE, organizador. Violência e política no Rio de Janeiro. Rio de Janeiro(RJ): Relume Dumará/ISER; 1996. p. 65-106.

10. Zalaf MRR, Fonseca RMGS. Na Boca do CRUSP: programa de prevenção e acolhimento em caso de uso problemático de álcool e drogas. Esc Anna Nery Rev Enferm 2007 dez; 11 (4): 650-54.

11 Paltiel FL. La salud mental de la mujer de las Américas. In: Organizacion Pan-Americana de la Salud- OPS. Gênero, mujer y salud em las Américas; 1993; 541: 143-61.

12 Fonseca RMGS. Equidade de gênero e saúde das mulheres. Rev Esc Enferm USP, 2005; 39(4): 450-459.

13 Franzoi NM Concepções de trabalhadores das equipes de saúde da família sobre violência de gênero. São Paulo (SP): Escola de Enfermagem/USP; 2007.

14 Guedes RN. Problematizando a vida e o trabalho de mulheres profissionais do cuidado em saúde. [trabalho de conclusão de curso]. João Pessoa (PB): Escola de Enfermagem/ UFP; 2004.

15 Pitangui J. Gênero, violência e direitos humanos. Promoção da Saúde. 2002; 6: 67-70.

16 Dantas-Berguer SM, Giffin K. A violência nas relações de conjugalidade: invisibilidade e banalização da violência sexual? Cad Saude Publica 2005; 21: 417-25.

17 Fonseca RMGS, Bertolozzi MR, organizadoras. A epidemiologia social e a assistência à saúde da população. In: Associação Brasileira de Enfermagem. A classificação das práticas de enfermagem em saúde coletiva e o uso da epidemiologia social. Brasília (DF): ABEn; 1997. p.1-60. Série Enfermagem em Saúde Coletiva. 